\title{
Pulmonary Function Test Quality in the Elderly: A Comparison With Younger Adults
}

\author{
Jeffrey M Haynes RRT RPFT
}

\begin{abstract}
BACKGROUND: Elderly patients may be at greater risk for misdiagnosis and inappropriate treatment as a consequence of pulmonary function test underutilization and tests being conducted with low quality expectations. This study sought to determine if elderly patients are able to achieve both spirometry and diffusion capacity $\left(\mathrm{D}_{\mathrm{LCO}}\right)$ quality scores comparable to a younger adult population. METHODS: This was a retrospective review of pulmonary function data over a 22 month period. A list of every subject age $\geq 80$ years (elderly group) and ages 40-50 years (control group) tested during the time period was compiled. The quality of spirometry and $\mathrm{D}_{\mathrm{LCO}}$ testing were examined. RESULTS: Overall, 92.6\% (139/150) of the elderly group and 91.5\% (163/178) of the control group spirometry tests satisfied all American Thoracic Society/European Respiratory Society acceptability and reproducibility criteria $(P=.84)$, and $84.9 \%(96 / 113)$ of the elderly group and $88.5 \%(108 / 122)$ of the control group $D_{L C O}$ tests satisfied all the acceptability and reproducibility criteria $(P=.45)$. CONCLUSIONS: Elderly patients referred to a hospital-based pulmonary function test lab can be expected to achieve spirometry and $D_{\mathrm{LCO}}$ quality scores comparable to younger adult patients. Key words: pulmonary function tests; spirometry; diffusing capacity; test quality. [Respir Care 2014;59(1):16-21. (c) 2014 Daedalus Enterprises]
\end{abstract}

\section{Introduction}

Elderly patients with cognitive impairment and apraxia have difficulty performing spirometry correctly. ${ }^{1,2}$ However, several studies have shown that most elderly patients can produce quality spirometry data. ${ }^{3-7}$ There are limited and conflicting data on the effect of age on the ability to perform diffusion capacity of the lung for carbon monoxide $\left(\mathrm{D}_{\mathrm{LCO}}\right)$ correctly. ${ }^{8,9}$ Elderly patients are at risk for misdiagnosis and inappropriate treatment of respiratory disease, ${ }^{10,11}$ which may be compounded by pulmonary function test (PFT) underutilization and the inappropriate acceptance of suboptimal test quality, due to low performance expectations. This study sought to determine if el-

\footnotetext{
Mr Haynes is affiliated with the Pulmonary Function Laboratory, St Joseph Hospital, Nashua, New Hampshire.

The author has disclosed no conflicts of interest.

Correspondence: Jeffrey M Haynes RRT RPFT, Pulmonary Function Laboratory, St Joseph Hospital, 172 Kinsley Street, Nashua NH 03060. E-mail: jhaynes@sjhnh.org.
}

DOI: $10.4187 /$ respcare.02331 derly patients referred to a hospital-based PFT laboratory are able to achieve both spirometry and $\mathrm{D}_{\mathrm{LCO}}$ quality scores comparable to a younger adult population.

\section{Methods}

This study was a retrospective review of PFT data over a 22 month period (June 2011 through March 2013) in a hospital-based PFT laboratory (St Joseph Hospital, Nashua, New Hampshire). The St Joseph Hospital institutional review board approved this study. Using the "research query tools" function of the PFT system (ComPAS, Morgan Scientific, Haverhill, Massachusetts) a list of every subject

See the Related Editorial on Page 127

age $\geq 80$ years (elderly group) tested during the time period was compiled. Every subject age $40-50$ years old tested during the same time frame served as the control group. Demographic data were collected and the quality of spirometry and $\mathrm{D}_{\mathrm{LCO}}$ testing were examined. The mean and median of the percent-of-predicted values and the percentage of test results below the lower limits of normal were recorded for $\mathrm{D}_{\mathrm{LCO}}, \mathrm{FVC}, \mathrm{FEV}_{1}$, and $\mathrm{FEV}_{1} / \mathrm{FVC}$. 
Our laboratory uses Global Lung Function Initiative (age range 3-95 years) ${ }^{12}$ and Cotes ${ }^{13}$ predicted equations for spirometry and $\mathrm{D}_{\mathrm{LCO}}$, respectively. American Thoracic Society/European Respiratory Society (ATS/ERS) quality standards were used to judge individual test quality. ${ }^{14,15}$ Our PFT system provides an on-screen display of effortby-effort test acceptability and reproducibility, and detailed grading of test quality based on the ATS/ERS quality standards ${ }^{14,15}$ (Figure). In addition to computerized quality scoring, each pulmonary function test was examined in detail by the chief technologist to confirm the accuracy of computer grading. FVC and $\mathrm{FEV}_{1}$ were graded on an A-B-C-D-F quality scale, as described in the Global Lungs Initiative Phase 2 Pilot Study ${ }^{16}$ (Table 1).

During this time period the laboratory was staffed by 3 technologists. Two technologists had $>20$ years of testing experience, and the third technologist had 5 years of testing experience. The chief technologist of the laboratory is a registered pulmonary function technologist. The laboratory's quality assurance program includes ongoing technologist performance surveillance and monthly and quarterly technologist performance feedback. ${ }^{17,18}$ Examination of the quality control records from the study period revealed no issues in terms of pneumotachograph or gas analyzer malfunction. Moreover, no out-of-control conditions were identified from the review of biologic control testing records.

\section{Statistical Analysis}

Commercially available software was used for statistical computations (Prism 4, StatMate 2.0, GraphPad Software, La Jolla, California). Differences in categorical data were examined with the Fisher exact test. Differences in continuous data were examined with the Student $t$ test for unpaired means, or the Mann-Whitney test for unpaired medians. Data are reported as mean $\pm \mathrm{SD}$ or median and IQR. Post hoc power analysis of test success for this 22 month sample was performed. A 2-tailed $P$ value of $<.05$ was considered significant.

\section{Results}

During the study period, 150 elderly subjects attempted 150 spirometry and $113 \mathrm{D}_{\mathrm{LCO}}$ tests. During the same time frame, 178 control subjects attempted 178 spirometry and $122 \mathrm{D}_{\mathrm{LCO}}$ tests. Demographic data are listed in Table 2. The elderly group had a lower FVC and $\mathrm{FEV}_{1}$, expressed as a percent of predicted, but not as a proportion of values below the lower limit of normal. The percentage of $\mathrm{FEV}_{1} / \mathrm{FVC}$ values below the lower limit of normal was not different between groups. $\mathrm{D}_{\mathrm{LCO}}$ was lower in the elderly group, both as a percent of predicted and as a proportion of values below the lower limit of normal.

\section{QUICK LOOK}

\section{Current knowledge}

Elderly patients may be at greater risk for misdiagnosis and inappropriate treatment as a consequence of underutilization of, and low quality expectations about, pulmonary function testing in the elderly. Comorbidities, including cognitive impairment and apraxia, may influence the quality of spirometry and diffusion-capacity testing.

\section{What this paper contributes to our knowledge}

This retrospective review suggests that the quality of spirometry and diffusion-capacity results in elderly patients is similar to that in young adults. Advanced age alone does not portend poor-quality spirometry or diffusion-capacity results.

\section{Spirometry Quality}

In the elderly group $92.6 \%$ (139/150) of the spirometry tests satisfied all the ATS/ERS acceptability and reproducibility criteria (grade A). ${ }^{14}$ Of the 11 tests that failed to meet all ATS/ERS performance standards, 3 had both FVC and $\mathrm{FEV}_{1}$ grades $\mathrm{C}$ or better. When those tests were included, $94.6 \%$ of tests produced clinically meaningful FVC and $\mathrm{FEV}_{1}$ data. ${ }^{16}$ Five tests had both $\mathrm{FVC}$ and $\mathrm{FEV}_{1}$ grades worse than $\mathrm{C}$, and 3 had an $\mathrm{FEV}_{1}$ grade $\mathrm{C}$ or better coupled with an FVC grade worse than C. The most common reason for test failure were inability to exhale for $\geq 6 \mathrm{sec}$ onds, and an extrapolated volume $>5 \%$ of the FVC or $>150 \mathrm{~mL}$.

In the control group 91.5\% (163/178) of spirometry tests satisfied all the ATS/ERS acceptability and reproducibility criteria (grade A). ${ }^{14}$ Of the 15 tests that failed to meet all ATS/ERS performance standards, 1 test had both FVC and $\mathrm{FEV}_{1}$ grades $\mathrm{C}$ or better. When that test was included, $92.1 \%$ of tests produced clinically meaningful $\mathrm{FVC}$ and $\mathrm{FEV}_{1}$ data. ${ }^{16}$ Three tests had both FVC and $\mathrm{FEV}_{1}$ grades worse than C, 10 tests had $\mathrm{FEV}_{1}$ grades $\mathrm{C}$ or better coupled with $\mathrm{FVC}$ grades worse than $\mathrm{C}$, and 1 test had an $\mathrm{FVC}$ grade $\mathrm{C}$ or better coupled with an $\mathrm{FEV}_{1}$ grade worse than $\mathrm{C}$. The most common reasons for test failure were inability to exhale for $\geq 6 \mathrm{sec}$ onds, extrapolated volume $>5 \%$ of the FVC or $>150 \mathrm{~mL}$, and failure to reach the peak expiratory flow within $1.2 \mathrm{sec}-$ onds. There was no difference in spirometry test quality between the groups $(P=.84$, Table 3$)$. Post hoc analysis revealed that this comparison had $80 \%$ power to detect an $8 \%$ difference in success, with a significance level of .05 (2tailed $P$ ).

\section{LCO $_{\text {Quality }}$}

In the elderly group $84.9 \%$ (96/113) of tests satisfied all the ATS/ERS acceptability and reproducibility criteria. ${ }^{15}$ Of 


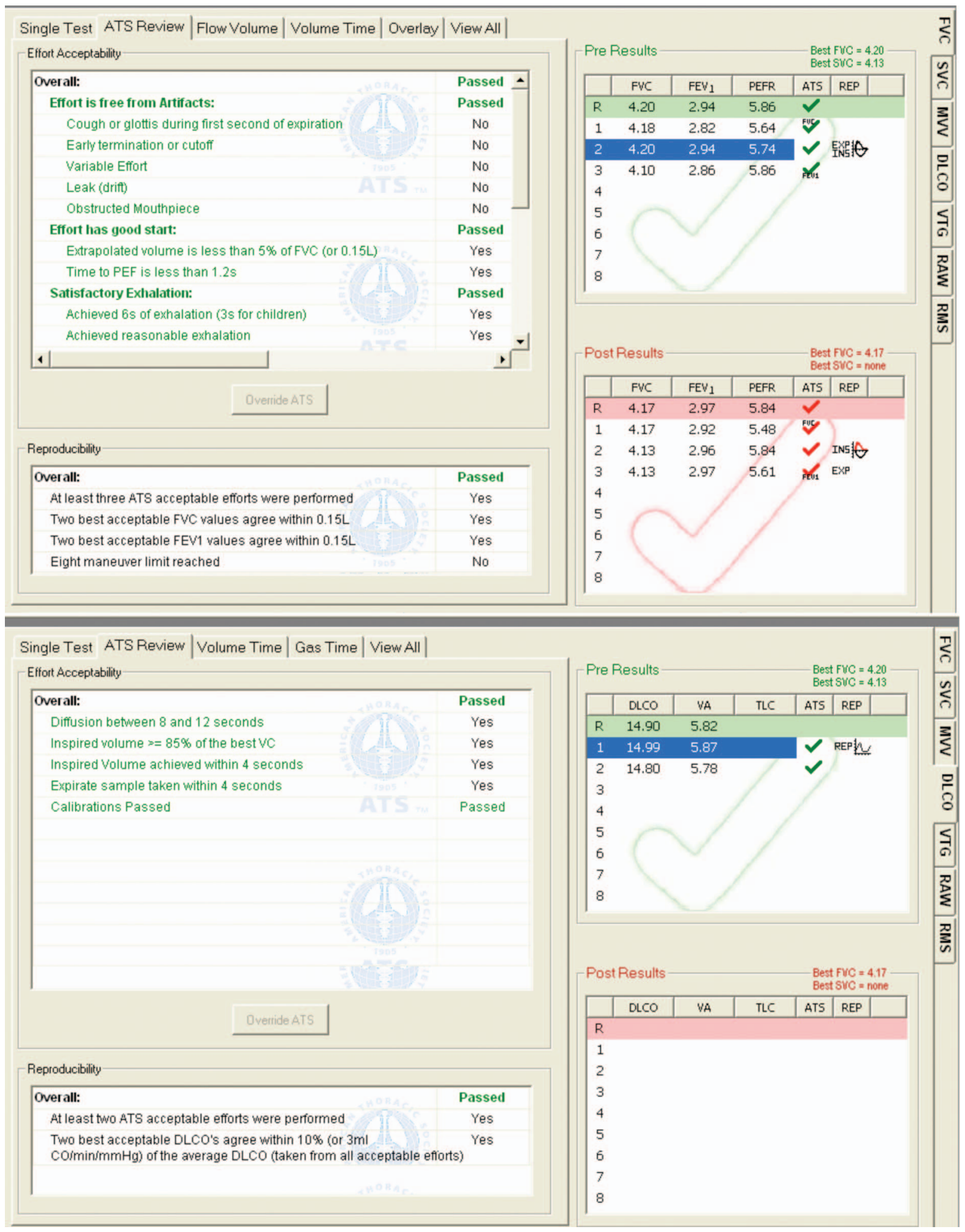

Figure. Screen shot of test acceptability and reproducibility for spirometry (upper panel) and diffusion capacity of the lung for carbon monoxide $\left(\mathrm{D}_{\mathrm{LCO}}\right)$ (lower panel) with the ComPAS pulmonary function test system. The small check marks indicate effort acceptability and the large central check mark indicates effort reproducibility.

the $17 \mathrm{D}_{\mathrm{LCO}}$ tests that failed to satisfy all ATS/ERS criteria, 1 test was performed correctly and was reproducible, but only failed to satisfy the acceptability criteria because severe airflow obstruction precluded capture of the alveolar sample 
Table 1. Quality Grades for FVC and $\mathrm{FEV}_{1}$

\begin{tabular}{ccc}
\hline \hline $\begin{array}{c}\text { Quality } \\
\text { Grade }\end{array}$ & $\begin{array}{c}\text { Acceptable } \\
\text { Efforts } \\
\text { (no.) }\end{array}$ & $\begin{array}{c}\text { Repeatability } \\
(\mathrm{mL})\end{array}$ \\
\hline FVC & & \\
A & 2 & $\leq 150$ \\
B & $\geq 2$ & $\leq 150$ \\
C & $\geq 2$ & $\leq 200$ \\
D & $\leq 1$ & $\leq 250$ \\
F & & NA \\
FEV & $\geq 3$ & $\leq 150$ \\
A & 2 & $\leq 150$ \\
B & $\geq 2$ & $\leq 200$ \\
C & $\geq 2$ & $\leq 250$ \\
D & $\leq 1$ & NA \\
F & & \\
\hline NA = not applicable & & \\
(From data in Reference 16.) & & \\
\hline
\end{tabular}

Table 2. Demographics

\begin{tabular}{|c|c|c|c|}
\hline & $\begin{array}{c}\text { Elderly } \\
n=150\end{array}$ & $\begin{array}{c}\text { Control } \\
n=178\end{array}$ & $P$ \\
\hline \multicolumn{4}{|l|}{ Age, y } \\
\hline Mean $\pm \mathrm{SD}$ & $83.9 \pm 3.4$ & $45.7 \pm 3.2$ & $<.001$ \\
\hline Median (IQR) & $83(81-86)$ & $46(43-49)$ & $<.001$ \\
\hline Female, no. $(\%)$ & $78 / 150(52)$ & $109 / 178(61.2)$ & $>.09$ \\
\hline White, no. (\%) & $149 / 150(99.3)$ & $168 / 178(94.3)$ & .01 \\
\hline \multicolumn{4}{|l|}{ FVC, no. (\%) predicted } \\
\hline Mean $\pm \mathrm{SD}$ & $82.5 \pm 18.31$ & $93.1 \pm 17.7$ & $<.001$ \\
\hline Median (IQR) & $85(71-94)$ & $95(82.5-105.5)$ & $<.001$ \\
\hline FVC $<$ LLN, no. (\%) & $32 / 147(21.7)$ & $32 / 176(18.2)$ & .48 \\
\hline \multicolumn{4}{|l|}{$\mathrm{FEV}_{1} \%$ predicted } \\
\hline Mean $\pm \mathrm{SD}$ & $76.5 \pm 22.9$ & $86.8 \pm 22.0$ & $<.001$ \\
\hline Median (IQR) & $79(60-94)$ & $89.5(76-102)$ & $<.001$ \\
\hline $\mathrm{FEV}_{1}<\mathrm{LLN}$, no. $(\%)$ & 49/147 (33.3) & $50 / 176(28.4)$ & .39 \\
\hline $\mathrm{FEV}_{1} / \mathrm{FVC}<\mathrm{LLN}$, no. $(\%)$ & 29/147 (19.7) & $39 / 176(22.1)$ & .68 \\
\hline \multicolumn{4}{|l|}{$\mathrm{D}_{\mathrm{LCO}} \%$ predicted } \\
\hline Mean $\pm \mathrm{SD}$ & $55.8 \pm 19.6$ & $80.3 \pm 17.4$ & $<.001$ \\
\hline Median (min-max) & $56(43-70)$ & $81(71.5-92)$ & $<.001$ \\
\hline $\mathrm{D}_{\mathrm{LCO}}<\mathrm{LLN}$, no. $(\%)$ & $57 / 103(55.3)$ & 22/116 (18.9) & $<.001$ \\
\hline
\end{tabular}

within 4 seconds. When that test was included, $85.8 \%$ of the $\mathrm{D}_{\mathrm{LCO}}$ tests were performed correctly and provided reproducible values.

In the control group $88.5 \%(108 / 122)$ of the tests satisfied all the ATS/ERS acceptability and reproducibility criteria. ${ }^{15}$ Of the $14 \mathrm{D}_{\mathrm{LCO}}$ tests that failed to satisfy all ATS/ERS criteria, 2 tests were performed correctly and were reproducible, but only failed to satisfy acceptability criteria because severe air-flow obstruction precluded capture of the alveolar sample within 4 seconds. When those tests were included, $90.2 \%$ of
Table 3. Spirometry and $\mathrm{D}_{\mathrm{LCO}}$ Quality

\begin{tabular}{lccc}
\hline \hline & $\begin{array}{c}\text { Elderly } \\
\text { no. (\%) }\end{array}$ & $\begin{array}{c}\text { Control } \\
\text { no. (\%) }\end{array}$ & $P$ \\
\hline Spirometry grade & & & \\
FVC and $\mathrm{FEV}_{1}=$ grade A & $139 / 150(92.6)$ & $163 / 178(91.5)$ & .84 \\
FVC and $\mathrm{FEV}_{1}$ grade C or & $142 / 150(94.6)$ & $164 / 178(92.1)$ & .39 \\
$\quad$ better & & & \\
$\mathrm{D}_{\text {LCO quality }}$ & & & \\
$\quad$ Met all standards & $96 / 113(84.9)$ & $108 / 122(88.5)$ & .45 \\
Performed correctly & $97 / 113(85.8)$ & $110 / 122(90.2)$ & .32
\end{tabular}

$\overline{\mathrm{D}_{\mathrm{LCO}}=\text { diffusion capacity of the lung for carbon monoxide }}$

the $\mathrm{D}_{\mathrm{LCO}}$ tests were performed correctly and provided reproducible values. There was no difference in $\mathrm{D}_{\mathrm{LCO}}$ test quality between the groups $(P=.45$, see Table 3$)$. Post hoc analysis revealed that this comparison had $80 \%$ power to detect a $12 \%$ difference in success, with a significance level of .05 (2tailed $P$ ).

\section{Discussion}

Undiagnosed respiratory disease and the underutilization of PFT in elderly patients are common, and the impact of undiagnosed disease is substantial. ${ }^{11,19}$ Indeed, undiagnosed COPD in older individuals has a significant effect on health-related quality of life. ${ }^{20}$ Dow et $a{ }^{10}$ reported that $84 \%$ of older patients with untreated asthma were found to have moderate to severe disease after spirometry testing was performed. In addition, elderly patients may more frequently be subjected to poorly conducted PFTs if the technologist has a preconceived notion that elderly patients are less likely to be able to perform PFTs correctly.

Diminished cognitive function and apraxia (inability to perform a motor activity from thought) in elderly patients with neurologic impairment can certainly make meaningful PFT data very difficult or impossible to obtain. Allen and Baxter ${ }^{1}$ studied the strength of cognitive tests to predict the ability of elderly subjects to perform spirometry correctly. Lower scores on the Mini Mental State Examination (overall cognition) and difficulty drawing intersecting pentagons were predictive of spirometry test failure. Interestingly, tests of executive function were found to be less predictive of outcome. Carvalhaes-Neto et $\mathrm{al}^{2}$ assessed the ability of elderly institutionalized subjects with cognitive dysfunction to perform spirometry testing. Only $41 \%$ of the subjects were able to perform spirometry correctly, and a lower Mini Mental State Examination score correlated with spirometry failure.

While it is clear that elderly patients with marked cognitive impairment and apraxia are less likely to perform spirometry (forced or slow ${ }^{21}$ ) correctly, most elderly patients without severe cognitive impairment are able to produce quality spirometry data.

Sherman and colleagues ${ }^{3}$ assessed the ability of 65 elderly subjects with only mild cognitive impairment to perform spi- 
rometry. Of the group, $87.6 \%$ of subjects were able to produce acceptable spirometry data. The Salute Respiratoria Dell' Anziano ${ }^{4}$ (SARA [Respiratory Health in the Elderly]) study collected spirometry data from patients with ages ranging from 65 to 100 years, using mostly inexperienced technicians. The SARA investigators reported that $78 \%$ of all the subjects produced 3 acceptable spirometry efforts. ${ }^{4}$ Pezzoli et al ${ }^{5}$ studied 715 elderly patients with respiratory symptoms and found that $81.8 \%$ were able to perform spirometry correctly. These and other studies ${ }^{6,7,21}$ clearly show that cognitive function, and not age itself, is predictive of successful or unsuccessful spirometry in elderly patients. Indeed, there are no data to suggest that younger patients with severe cognitive impairment would perform spirometry any better than elderly patients with similar cognitive deficits.

There are far less data regarding the effect of age on the ability to perform $\mathrm{D}_{\mathrm{LCO}}$ correctly. In a general population study conducted in the 1980 s, Welle et $\mathrm{al}^{8}$ found that only $67 \%$ of adult subjects could perform $\mathrm{D}_{\mathrm{LCO}}$ testing correctly, and that younger age was an independent predictor of test failure. The Welle study differed from current practice because the minimally acceptable ratio of inspired vital capacity to FVC was 0.9 , which is higher than the current standard $0.85 .{ }^{15}$ It is also notable that one technologist with unspecified experience performed $96 \%$ of the tests. Neas and Schwartz 9 examined $\mathrm{D}_{\mathrm{LCO}}$ data from the first National Health and Nutrition Examination Survey (1971-1975). Missing $\mathrm{D}_{\mathrm{LCO}}$ data (it is assumed that the patient could not perform the test properly) occurred in $40 \%$ of subjects aged $65-74$ years and in $22 \%$ of subjects aged 25-54 years. In contrast to the current study, both of those studies used data collected with older instrumentation that did not have quality control software, and analyzed data approximately 10 and 20 years, respectively, after it was originally collected.

In the present study $92.6 \%$ and $84.9 \%$ of the elderly subjects were able to perform both spirometry and $\mathrm{D}_{\mathrm{LCO}}$ tests to the satisfaction of ATS/ERS acceptability and reproducibility standards, respectively. ${ }^{14,15}$ Despite a higher prevalence of age-adjusted abnormal lung function $\left(\mathrm{D}_{\mathrm{LCO}}\right)$, there was no difference in the percentage of high quality tests between the elderly group (median age 83 years) and the much younger control group (median age 46 years). This study differs from many studies of spirometry quality in the elderly because this study used data from patients 80 years and older, whereas several previously published studies used data from patients aged 65 years and older. ${ }^{3-6}$

A contributing factor to the high quality scores documented in this study is our laboratory's use of a quality assurance program, which includes ongoing technologist performance surveillance and monthly and quarterly technologist performance feedback. The goal of our laboratory is that $90 \%$ of all tests meet ATS/ERS acceptability and reproducibility standards. ${ }^{22}$ Data supporting technologist performance feedback originated from the Lung Health Study. ${ }^{18}$ Enright and the
Lung Health Study Research Group showed that technologist performance was vacillating until a program of technologist monitoring and feedback was instituted. The SARA study utilized a technologist monitoring and feedback program, and, as cited earlier, was able to obtain quality spirometry data from $78 \%$ of elderly patients, even with inexperienced technologists. ${ }^{4}$ More recently, Borg and colleagues ${ }^{23}$ documented that adherence to spirometry quality standards increased from $61 \%$ to $92 \%$ in a hospital-based PFT lab after a technologist performance feedback program was initiated. While technologist monitoring and feedback is an ATS/ERS quality assurance recommendation, ${ }^{17}$ as few as $30 \%$ of laboratories may have such a program in place. ${ }^{24}$

PFTs should be conducted with the goal of collecting data of the highest quality; however, spirometry data with less than grade A quality should not necessarily be classified as invalid and go unreported. Hankinson et al ${ }^{16}$ examined the impact of FVC and $\mathrm{FEV}_{1}$ quality grades (see Table 1) on predicted reference equations. Only FVC and $\mathrm{FEV}_{1}$ data with grades of $\mathrm{D}$ and $\mathrm{F}$ negatively impacted the formulation of predicted values and lower limits of normal. Average $\mathrm{Z}$ scores for $\mathrm{FVC}$ and $\mathrm{FEV}_{1}$ were similar from data with A-C quality grades. In clinical practice, spirometry tests with grades $\mathrm{B}$ and $\mathrm{C}$, while not perfect, in most cases should be reported. In the current study the percentage of spirometry tests in the elderly group characterized as valid and meaningful increased from $92.6 \%$ to $94.6 \%$ with the inclusion of tests with B and $\mathrm{C}$ grades.

The present study has limitations. The subjects were from a population with little diversity in terms of culture and race. However, there is no reason to believe that the same level of PFT quality should not be achievable in any community. In a study of $6,193 \mathrm{D}_{\mathrm{LCO}}$ tests, Punjabi and colleagues ${ }^{25}$ found no association between race and test reproducibility. Differences in regional PFT referral practices could significantly impact test quality. A laboratory that serves physicians who regularly refer patients with substantial cognitive impairment and apraxia may experience less success when testing an elderly population. In addition, this study reports data from a community hospital laboratory with 3 experienced staff members; results might differ in larger laboratories with more diversity in technologist experience and skill level. Similar studies in different communities and laboratory settings are warranted.

It has been suggested that the Cotes ${ }^{13} \mathrm{D}_{\mathrm{LCO}}$ reference equations may not be ideal for older patients, since, like most $\mathrm{D}_{\mathrm{LCO}}$ reference equations, there was limited sampling of elderly subjects. ${ }^{26}$ Garcia-Rio et al ${ }^{26}$ published predicted equations for $\mathrm{D}_{\mathrm{LCO}}$ in patients aged 65-85 years, and a comparison with the Cotes ${ }^{13}$ equation suggested that the Cotes equation underestimates $\mathrm{D}_{\mathrm{LCO}}$ in elderly men and women. However, we have found the Cotes equations to function well in our patient population. The $\mathrm{D}_{\mathrm{LCO}}$ equation that best agreed with the Garcia-Rio equation was that of Crapo and Morris, ${ }^{27}$ 


\section{Pulmonary Function Test Quality in the Elderly}

which we believe overestimates $\mathrm{D}_{\mathrm{LCO}}$ in both our young and elderly patients. It is noteworthy that the Garcia-Rio ${ }^{26}$ and $\mathrm{Crapo}^{27}$ equations were generated using data collected at altitudes of 655 meters and 1,400 meters above sea level, respectively, whereas Nashua, New Hampshire, has an altitude of 50 meters above sea level. $\mathrm{D}_{\mathrm{LCO}}$ is well known to be positively correlated with altitude. ${ }^{28}$

\section{Conclusions}

The overwhelming majority of elderly patients referred to a hospital-based PFT laboratory performed spirometry and $\mathrm{D}_{\mathrm{LCO}}$ testing to the satisfaction of ATS/ERS acceptability and reproducibility standards. Elderly patients are capable of producing quality spirometry and $\mathrm{D}_{\mathrm{LCO}}$ data comparable to younger adults. Advanced age alone should not discourage patient referrals for PFTs or lower expectations for a high quality test.

\section{REFERENCES}

1. Allen SC, Baxter M. A comparison of four tests of cognition as predictors of inability to perform spirometry in old age. Age Ageing 2009 38(5):537-541.

2. Carvalhaes-Neto N, Lorino H, Gallinari C, Escolano S, Mallet A, Zerah $\mathrm{F}$, et al. Cognitive function and assessment of lung function in the elderly. Am J Respir Crit Care Med 1995;152(5):1611-1615.

3. Sherman CB, Kern D, Richardson ER, Hubert M, Fogel BS. Cognitive function and spirometry performance in the elderly. Am Rev Respir Dis 1993;148(1):123-126.

4. Bellia V, Pistelli R, Catalano F, Antonelli-Incalzi R, Grassi V, Meillo G, et al. Quality control of spirometry in the elderly: the SARA study. Am J Respir Crit Care Med 2000;161(4 Pt 1):1094-1100.

5. Pezzoli L, Giardini G, Consonni S, Dallera I, Bilotta C, Ferrario G, et al. Quality of sprirometric performance in older people. Age Ageing 2003;32(1):43-46.

6. Bellia V, Sorino C, Catalano F, Augugliaro G, Scichilone N, Pistelli $\mathrm{R}$, et al. Validation of $\mathrm{FEV}_{6}$ in the elderly: correlates of performance and repeatability. Thorax 2008;63(1):60-66.

7. Allen S, Yeung P, Janczewski M, Siddique N. Predicting inadequate spirometry technique and the use of $\mathrm{FEV}_{1} / \mathrm{FEV}_{3}$ as an alternative to $\mathrm{FEV}_{1} / \mathrm{FVC}$ for patients with mild cognitive impairment. Clin Respir J 2008;2(4):208-213.

8. Welle I, Eide GE, Bakke P, Gulsvik A. Applicability of the singlebreath carbon monoxide diffusing capacity in a Norwegian community study. Am J Respir Crit Care Med 1998;158(6):1745-1750.

9. Neas LM, Schwartz J. The determinants of pulmonary diffusing capacity in a national sample of U. S. adults Am J Respir Crit Care Med 1996;153(2):656-664.

10. Dow L, Fowler L, Phelps L, Waters K, Coggon D, Kinmonth AL, Holgate ST. Prevalence of untreated asthma in a population sample of 6000 older adults in Bristol, UK. Thorax 2001;56(6):472-476.

11. Connolly MJ. Obstructive airways disease: a hidden disability in the aged. Age Ageing 1996;25(4):265-267.
12. Quanjer PH, Stanojevic S, Cole TJ, Baur X, Hall GL, Culver BH, et al. Multi-ethnic reference values for spirometry for the 3-95-yr age range: the global lung function 2012 equations. Eur Respir J 2012;40(6):1324-1343.

13. Cotes JE, Chinn DJ, Quanjer PH, Roca J, Yernault JC. Standardization of the measurement of transfer factor (diffusing capacity). Report working party standardization of the lung function tests, European Community for Steel and Coal Official statement of the European Respiratory Society Eur Respir J Suppl 1993;16:41-52.

14. Miller MR, Hankinson J, Brusasco V, Burgos F, Cassaburi R, Coates A. et al. Standardisation of spirometry. Eur Respir J 2005;26(2):319-338.

15. MacIntyre N, Crapo RO, Viegi G, Johnson DC, van der Grinten CP, Brusasco V. et al. Standardisation of the single-breath determination of carbon monoxide uptake in the lung. Eur Respir J 2005;26(4):720-735.

16. Hankinson JL, Quanjer P, Stocks J, Hall GL, Eschenbacher B, Enright $\mathrm{P}$, et al. Use of $\mathrm{FVC}$ and $\mathrm{FEV}_{1}$ quality criteria to select subjects for inclusion in research studies (abstract). Am J Respir Crit Care Med 2011;183:A3309.

17. Miller MR, Crapo R, Hankinson J, Brusasco V, Burgos F, Casaburi $\mathrm{R}$, et al. General considerations for lung function testing. Eur Respir J 2005;26(1):153-161.

18. Enright PL, Johnson LR, Connett JE, Voelker H, Buist AS. Spirometry in the lung health study. 1. Methods and quality control. Am Rev Respir Dis 1991;143(6):1215-1223.

19. Apostolovic S, Jankovic-Tomasevic R, Salinger-Martinovic S, Djordjevic-Radojkovic D, Stanojevic D, Pavlovic M, et al. Frequency and significance of unrecognized chronic obstructive pulmonary disease in elderly patients with stable heart failure. Aging Clin Exp Res 2011;23(5-6):337-342.

20. Miravitlles M, Soriano JB, García-Río F, Muñoz L, Duran-Tauleria E, Sanchez G, et al. Prevalence of COPD in Spain: impact of undiagnosed COPD on quality of life and daily life activities. Thorax 2009;64(10):863-868.

21. Allen SC, Charlton C, Backen W, Warwick-Sanders M, Yeung P. Performing slow vital capacity in older people with and without cognitive impairment-is it useful? Age Ageing 2010;39(5):588-591.

22. Enright PL, Beck KC, Sherrill DL. Repeatability of spirometry in 18,000 adult patients. Am J Respir Crit Care Med 2004;169(2):235-238.

23. Borg BM, Hartley MF, Bailey MJ, Thompson BR. Adherence to acceptability and repeatability criteria for spirometry in complex lung function laboratories. Respir Care 2012;57(12):2032-2038.

24. Haynes JM. Comprehensive quality control for pulmonary function testing: it's time to face the music (editorial). Respir Care. 2010; 55(3):355-357.

25. Punjabi NM, Shade D, Patel AM, Wise RA. Measurement variability in single-breath diffusing capacity of the lung. Chest 2003;123(4): 1082-1089.

26. Garcia-Rio F, Dorgham A, Galera R, Casitas R, Martinez E, AlvarezSala R, Pino JM. Prediction equations for single-breath diffusing capacity in subjects aged 65 to 85 years. Chest 2012;142(1):175-184.

27. Crapo RO, Morris AH. Standardized single breath normal values for carbon monoxide diffusing capacity. Am Rev Respir Dis 1981;123(2): 185-189.

28. DeGraff AC, Grover RF, Johnson RL, Hammond JW, Miller JM. Diffusing capacity of the lung in Caucasians native to $3,100 \mathrm{~m}$. J Appl Physiol 1970;29(1):71-76.

This article is approved for Continuing Respiratory Care Education credit. For information and to obtain your CRCE

(free to AARC members) visit www.rcjournal.com

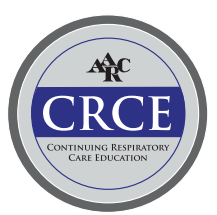

